\title{
Novel Effective Catalyst for Elemental Mercury Removal From Coal-Fired Flue Gas and the Mechanism Investigation
}

\author{
Wanmiao Chen, Yang Pei, Wenjun Huang, Zan Qu, Xiaofang Hu, Naiqiang Yan*
}

School of Environmental Science and Engineering, Shanghai Jiao Tong University, 800 Dong Chuan Road, Shanghai, 200240, PR China. E-mail addresses: nqyan@sjtu.edu.cn Fax: +86 21 54745591; Tel: +862154745591

11 pages, 7 figures 
The preparation method of the Ce-Zr solid solution.......................................S3

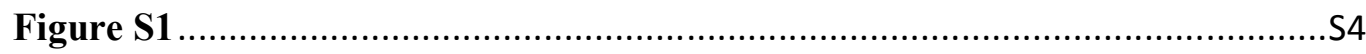

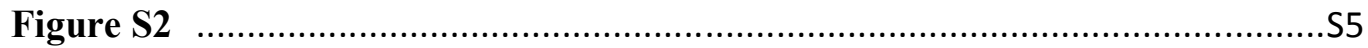

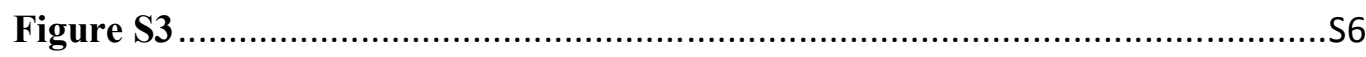

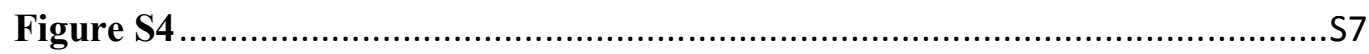

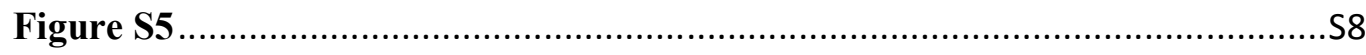

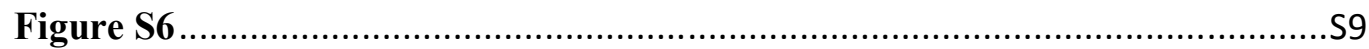

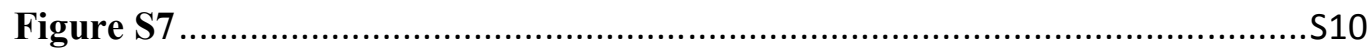

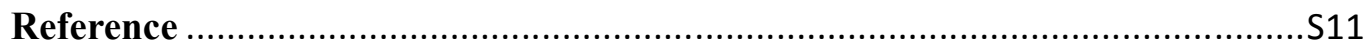




\section{The preparation method of the Ce-Zr solid solution}

The Ce-Zr solid solution carrier was prepared through sol-gel method. First, $0.6 \mathrm{~g}$ of Pluronic P123 (Mav = 5800, EO20PO70EO20, Aldrich) was dissolved in $10 \mathrm{~mL}$ ethanol. Then $\mathrm{Ce}\left(\mathrm{NO}_{3}\right)_{3} \cdot 6 \mathrm{H}_{2} \mathrm{O}$ and $\mathrm{Zr}\left(\mathrm{NO}_{3}\right) \cdot 5 \mathrm{H}_{2} \mathrm{O}$ were added as metal precursor (total amount of $\mathrm{Ce}$ and $\mathrm{Zr}$ is $5 \mathrm{mmol}$ ). After electromagnetic stirring for $10 \mathrm{~h}$ at room temperature, the sol was transferred to an oven under $40^{\circ} \mathrm{C}$ and underwent solvent evaporation. After aging for $48 \mathrm{~h}$, the gel product was dried at $100^{\circ} \mathrm{C}$ for $24 \mathrm{~h}$. Then, they were calcined at $400{ }^{\circ} \mathrm{C}$ for $5 \mathrm{~h}$ in air with $1{ }^{\circ} \mathrm{C} / \mathrm{min}$ ramping rate from room temperature ${ }^{1}$. 


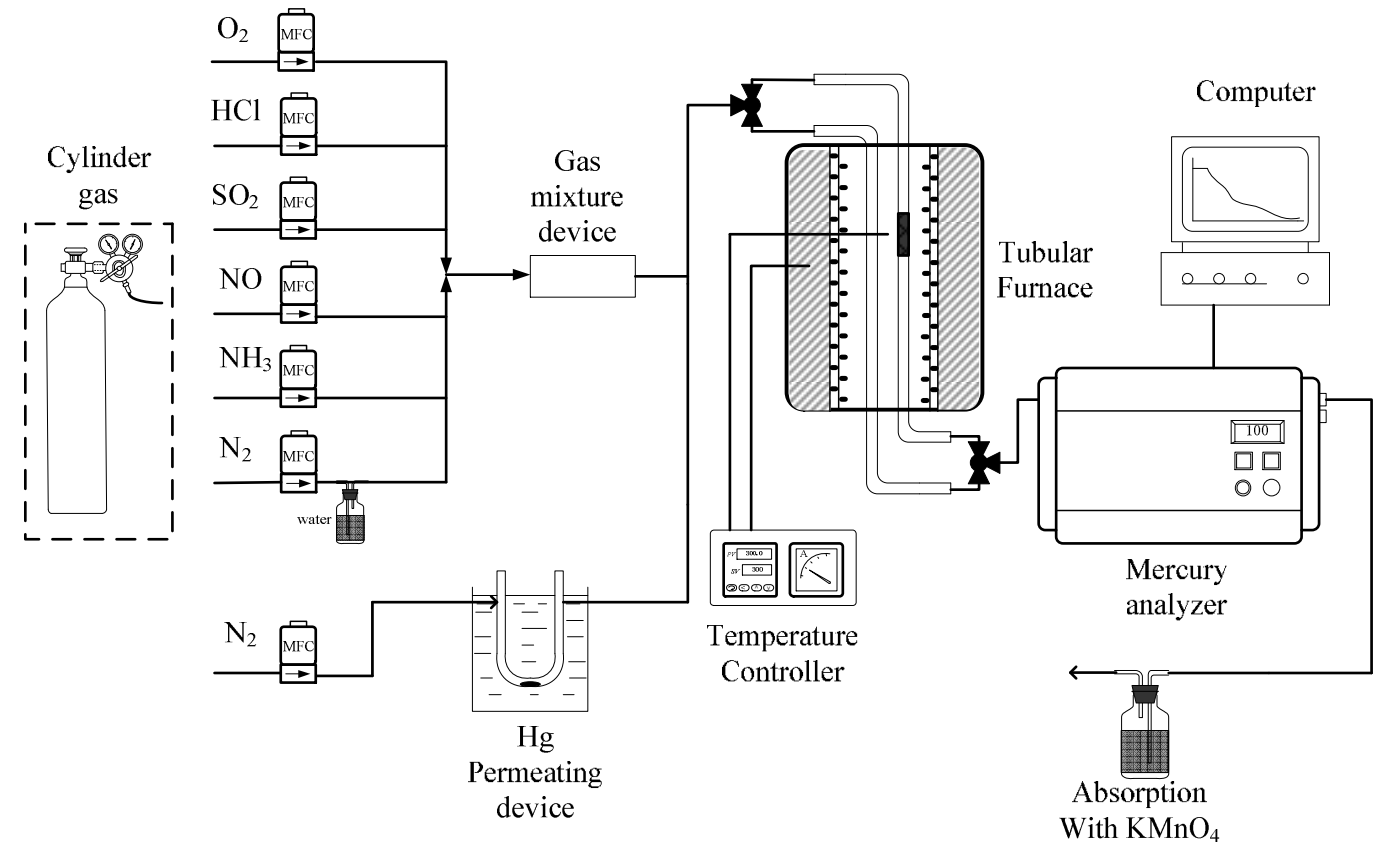

Figure S1 The experimental system 


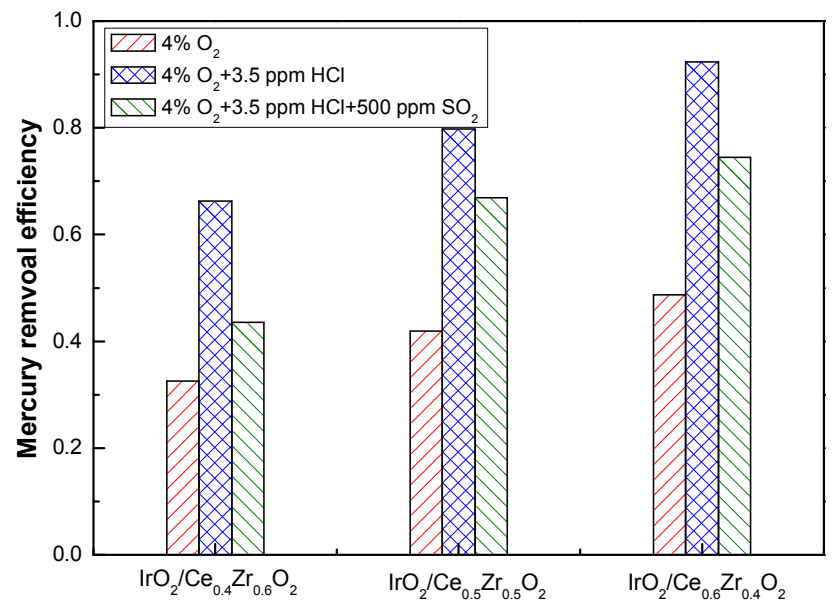

Figure S2 The catalytic oxidation of $\mathrm{Hg}^{\mathbf{0}}$ over various catalysts under different condition at $350{ }^{\circ} \mathrm{C}$

Reaction conditions: $500 \mathrm{ppm} \mathrm{SO}_{2} ; \mathrm{O}_{2}, 4$ vol.\%; $\mathrm{N}_{2}$ as carrier; flow rate, $500 \mathrm{ml} / \mathrm{min}$; catalyst weight, $30 \mathrm{mg}$. The space velocity (SV) was approximately $7.6 \times 10^{5} \mathrm{~h}^{-1}$. 

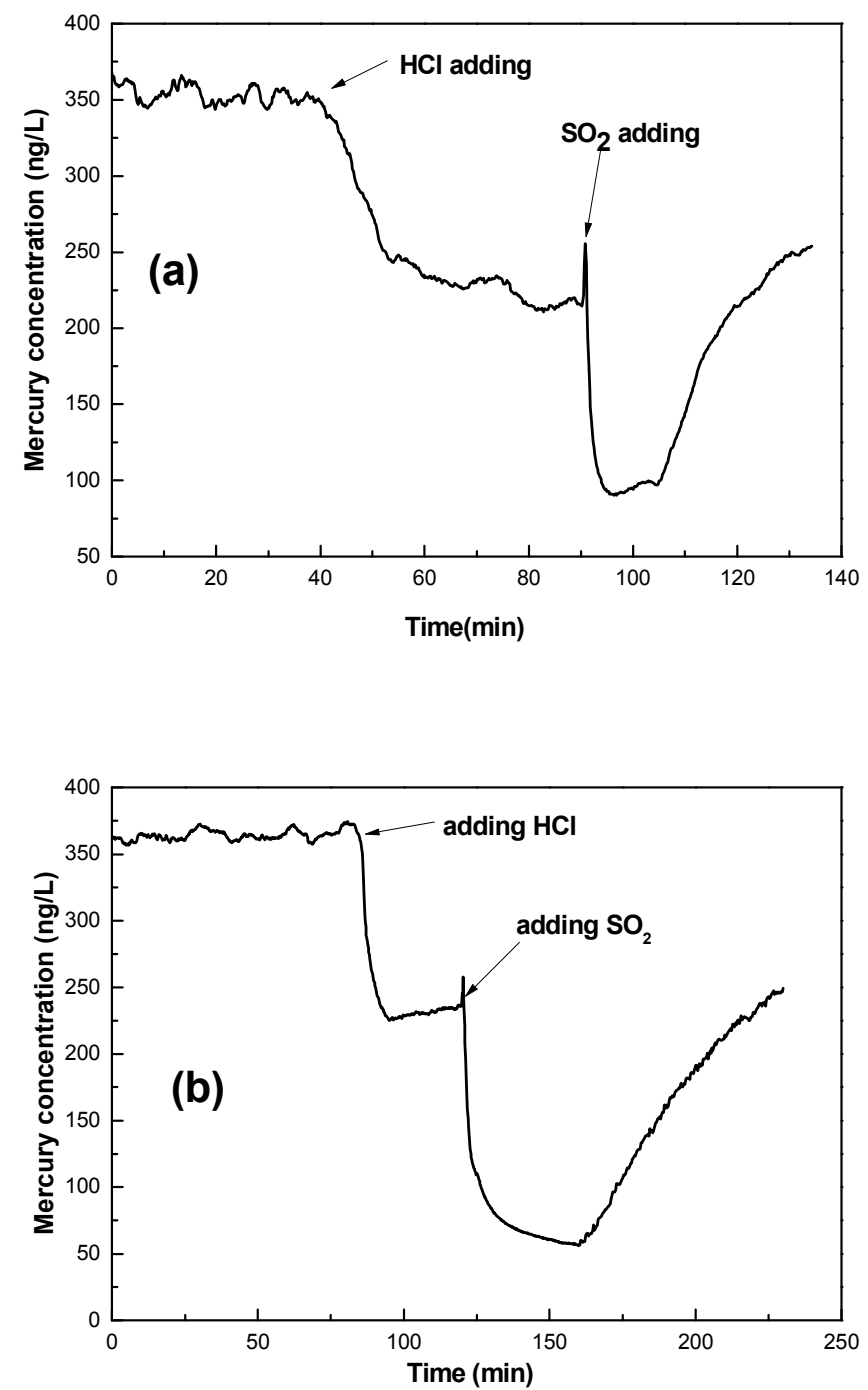

Figure $\mathrm{S3}$ The catalytic oxidation of $\mathrm{Hg}^{0}$ over $\mathrm{Ce}_{0.6} \mathrm{Zr}_{0.4} \mathrm{O}_{2}$ with different condition at $350{ }^{\circ} \mathrm{C}(\mathrm{a})$ and $150{ }^{\circ} \mathrm{C}(\mathrm{b})$

Reaction conditions: $500 \mathrm{ppm} \mathrm{SO}_{2} ; \mathrm{O}_{2}, 4$ vol. $\% ; \mathrm{N}_{2}$ as carrier; flow rate, $500 \mathrm{ml} / \mathrm{min}$; catalyst weight, $30 \mathrm{mg}$. The space velocity (SV) was approximately $7.6 \times 10^{5} \mathrm{~h}^{-1}$. 


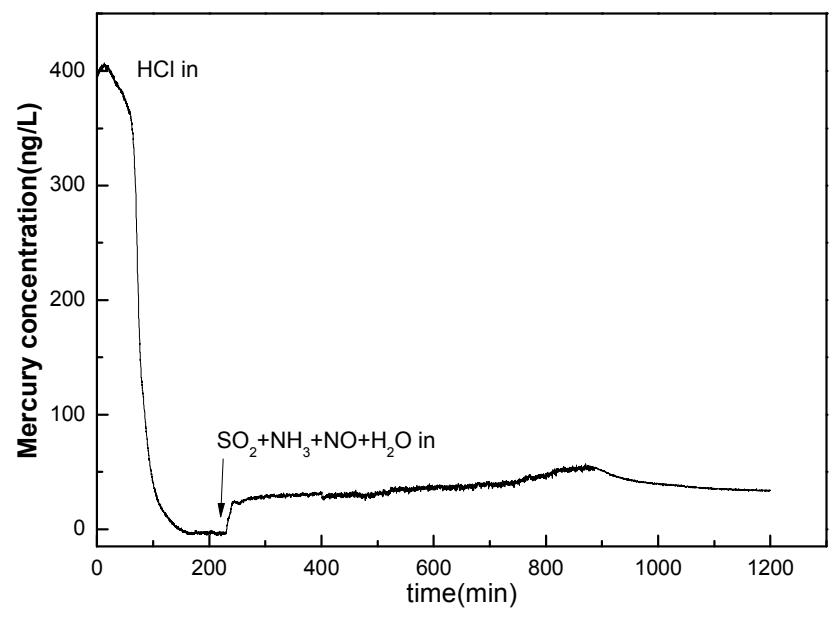

Figure S4 The catalytic oxidation of $\mathrm{Hg}^{0}$ over $\mathrm{IrO}_{2} / \mathrm{Ce}_{0.6} \mathrm{Zr}_{0.4} \mathrm{O}_{2}$ (PVP) with simulated coal-fired flue gas at $350{ }^{\circ} \mathrm{C}$

Reaction conditions: 10 ppm HCl; 500ppm SO $2 ; \mathrm{NH}_{3} 50$ ppm; NO 50ppm; 4\% $\mathrm{H}_{2} \mathrm{O}$;

$\mathrm{O}_{2}, 4$ vol.\%; $\mathrm{N}_{2}$ as carrier; flow rate, $200 \mathrm{ml} / \mathrm{min}$; catalyst weight, $100 \mathrm{mg}$. The space velocity (SV) was approximately $9.0 \times 10^{4} \mathrm{~h}^{-1}$. 


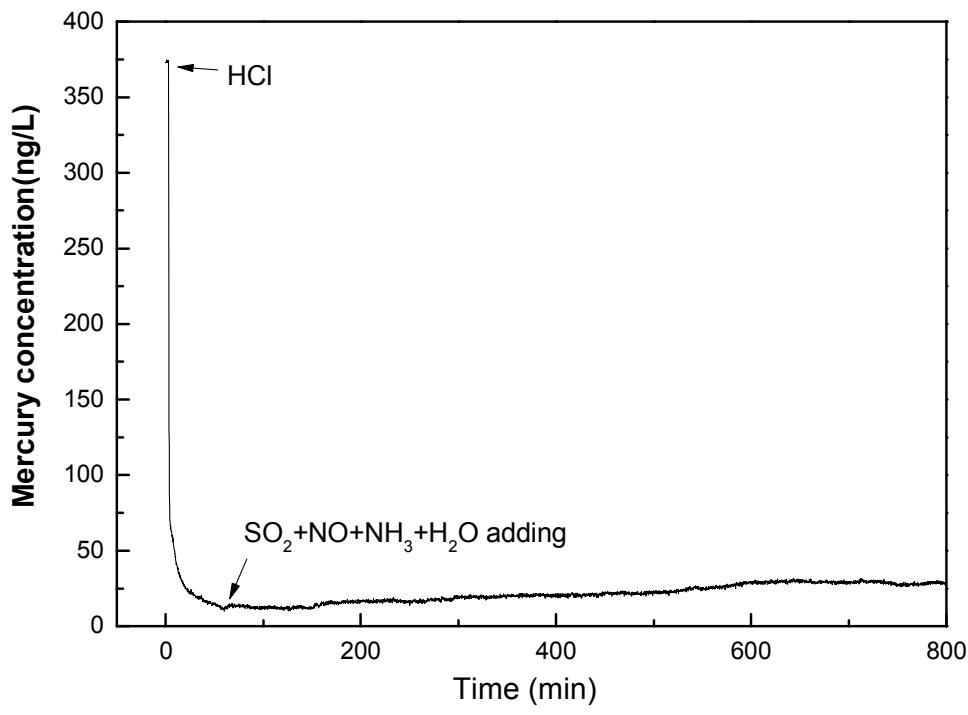

Figure S5 The catalytic oxidation of $\mathrm{Hg}^{0}$ over $\mathrm{IrO}_{2} / \mathrm{Ce}_{0.6} \mathrm{Zr}_{0.4} \mathrm{O}_{2}$ (PVP) with simulated coal-fired flue gas at $150{ }^{\circ} \mathrm{C}$

Reaction conditions: 10 ppm HCl; 500ppm SO $2 ; \mathrm{NH}_{3} 50$ ppm; $\mathrm{NO} 50 \mathrm{ppm} ; 4 \% \mathrm{H}_{2} \mathrm{O}$;

$\mathrm{O}_{2}, 4$ vol.\%; $\mathrm{N}_{2}$ as carrier; flow rate, $200 \mathrm{ml} / \mathrm{min}$; catalyst weight, $100 \mathrm{mg}$. The space velocity (SV) was approximately $9.0 \times 10^{4} \mathrm{~h}^{-1}$. 


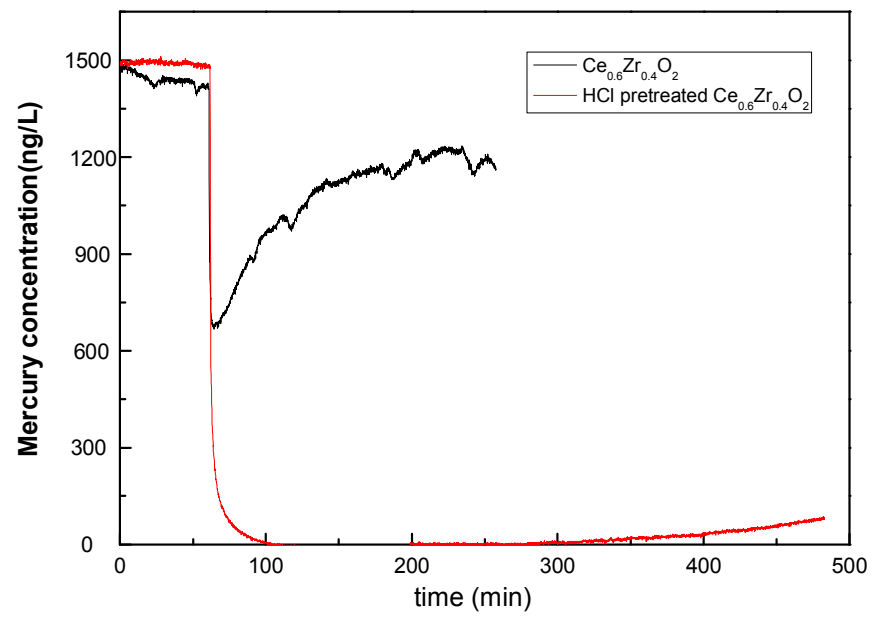

Figure S6 The adsorption curve over $\mathrm{Ce}_{0.6} \mathrm{Zr}_{0.4} \mathrm{O}_{2}$

Reaction conditions: 4 vol.\%; $\mathrm{N}_{2}$ as carrier; flow rate, $500 \mathrm{ml} / \mathrm{min}$; catalyst weight, $30 \mathrm{mg}$. The space velocity (SV) was approximately $7.6 \times 10^{5} \mathrm{~h}^{-1}$. The temperature is $350{ }^{\circ} \mathrm{C}$ 

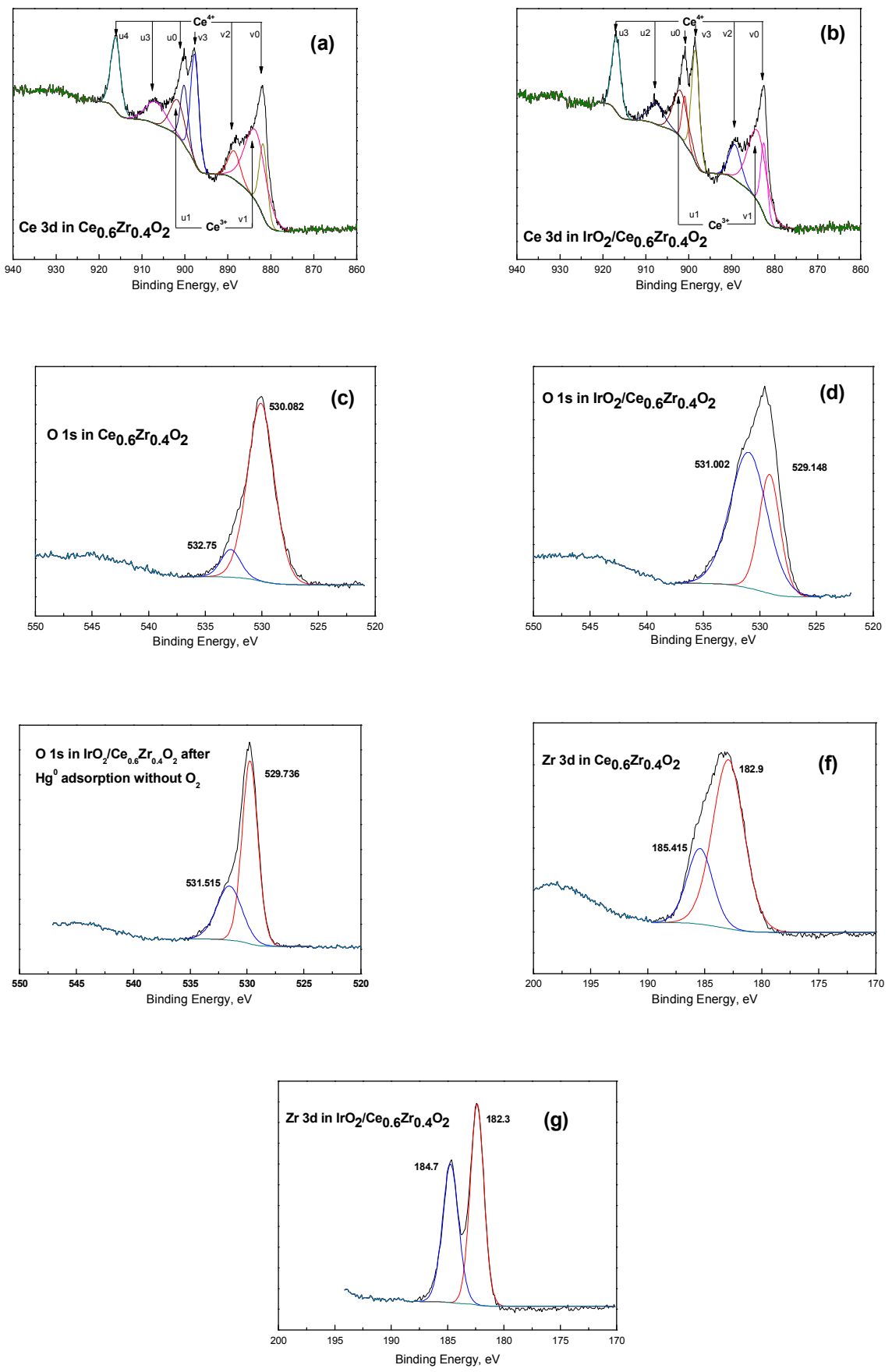

Figure S7 The XPS spectra of $\mathrm{Ce}, \mathrm{O}$ and $\mathrm{Zr}$ in various catalysts 


\section{Reference}

1. Yu, T.; Zeng, J.; Lim, B.; Xia, Y., Aqueous - Phase Synthesis of Pt/CeO2 Hybrid Nanostructures and Their Catalytic Properties. Advanced Materials 2010, 22, (45), 5188-5192. 